\title{
O Aedes Aegypti e a Dengue: Aspectos Gerais e Panorama da Dengue no Brasil e no Mundo
}

\section{Aedes Aegypti and Dengue: General Aspects and Dengue Panorama in Brazil and in the World}

\author{
Luciana Dias Lemes de Vargas; ${ }^{\mathrm{a}}$ Darlene Miranda de Freitas $;$; Bruna Rosa dos Santos ${ }^{\mathrm{a}}$; Mari Rose de Oliveira Silva ${ }^{\mathrm{a}}$; \\ Marcelo Dias de Souza ${ }^{a}$; Walkiria Shimoya-Bittencourt*a
}

aUniversidade de Cuiabá, Programa de Pós-Graduação Stricto Sensu em Ambiente e Saúde. MT, Brasil.

*E-mail: wshimoya@yahoo.com.br

\begin{abstract}
Resumo
A dengue, transmitida através da picada do mosquito Aedes Aegypti, é considerada uma doença endêmica e com disseminação mundial, podendo evoluir, de forma branda a grave, e até mesmo letal. Os países, com clima tropical, quente e úmido, como o Brasil, possuem condições favoráveis e facilitadoras para a reprodução do seu vetor e aumento da cadeia de transmissibilidade e contaminação, tornando um sério problema de saúde pública. Diante deste cenário, o propósito deste estudo foi sintetizar as informações disponíveis sobre o Aedes aegypti e a dengue, abrangendo aspectos gerais da doença e o panorama da dengue no Brasil e no Mundo, a fim de compilar material educativo. Os estudos relacionados ao tema foram encontrados mediante busca na Biblioteca Virtual em Saúde, PubMed e Embase. Também foram consultados documentos do Ministério da Saúde e Organização Mundial da Saúde sobre o manejo da dengue. A dengue é um grave problema de saúde pública, com diversas condições facilitadoras de transmissão, quatro diferentes sorotipos, que propicia reinfecção, sem tratamento específico e nem vacina disponível. Dessa forma, o meio mais eficaz de evitar sua propagação é pela prevenção. Para isso, as pessoas em todo Mundo devem ter o conhecimento e informações necessárias sobre prevenção, diagnóstico e tratamento, a fim de evitar sua transmissão, disseminação e letalidade.
\end{abstract}

Palavras-chave: Dengue. Aedes aegypti. Aspectos Gerais. Saúde Pública.

\begin{abstract}
Dengue, transmitted through the bite of Aedes Aegypti mosquito, is considered an endemic disease with worldwide spread, and can evolve from mild to severe and even lethal. Countries with tropical, hot and humid climates, such as Brazil, have favorable and facilitating conditions for the reproduction of their vector and an increase in the transmissibility and contamination chain, making it a serious public health problem. Given this scenario, the purpose of this study was to synthesize the available information on Aedes aegypti and dengue, covering general aspects of the disease and the dengue panorama in Brazil and in the world in order to compile educational material. The studies related to the theme were found by searching the Virtual Health Library, PubMed and Embase. Documents from the Ministry of Health and the World Health Organization on dengue management were also consulted. Dengue is a serious public health problem, with several conditions that facilitate transmission, four different serotypes that provide reinfection, with no specific treatment and no vaccine available. Thus, the most effective way to prevent its spread is through prevention. Thus, people all over the world must have the necessary knowledge and information on prevention, diagnosis and treatment, in order to avoid its transmission, dissemination and lethality.
\end{abstract}

Keywords: Dengue. Aedes aegypti. General Aspects. Public Health.

\section{Introdução}

Ao longo da história da humanidade, o ambiente em que se vive vem se modificando, principalmente, em consequência do êxodo rural e crescimento urbano, pois as populações estão transformando o espaço rural em espaço urbano. A partir desses eventos foram criadas condições, que permitiram aos animais aproximação com as populações humanas, propiciando o surgimento de inúmeras doenças conhecidas como arboviroses (WERMELINGER, 2013).

Atualmente, em todo o Mundo há milhares de microorganismos de diversas espécies, em quantidade altamente patógena aos animais e ao homem. No entanto, a maioria das doenças transmitidas necessita uma rede ou cadeia de transmissão, sendo necessário um meio transportador, isto é, algo que leve um agente patógeno a passar de um hospedeiro a outro, a fim de se reproduzir, desenvolver, reproduzir e se multiplicar (TAUIL, 2006). Ademais, o vetor é o ser vivo capaz de realizar a transmissão de um micro-organismo infeccioso ou patógeno de um ser para outro. Ele é o veículo indispensável para que ocorra uma contaminação, como ocorre na dengue (DONALISIO; VIDRO, 2002).

$\mathrm{O}$ aedes aegypti, mosquito transmissor da dengue, não é um inseto originário do Brasil, porém o clima tropical, altas temperaturas, umidade e estações chuvosas são facilitadores para que esse inseto esteja presente em muitas localidades do país e outros lugares do Mundo com clima semelhante (GARCIA, 2019).

A dengue é motivo de grande preocupação das autoridades de saúde pública, tanto no Brasil quanto em outros países, pois o mosquito aedes aegypti apresenta uma ampla disseminação e evolução em relação às condições de sua sobrevivência, tornando-se um inseto adaptável às situações não favoráveis 
para a sua existência (BESERRA; CASTRO JR., 2008).

Há evidências de que haja em torno de quatro bilhões de pessoas vivendo em áreas de risco para a dengue, 390 milhões de casos registrados no Mundo e 96 milhões de pessoas com os sintomas clínicos de dengue. Nas Américas, a transmissão e a disseminação da dengue ocorrem em surtos, de forma cíclica, com média de 3 a 5 anos. No entanto, no Brasil essa disseminação ocorre, de forma contínua, desde 1986, com os maiores surtos acontecendo, a partir de 2014 (AMARAL; PETRESTSKI, 2012).

Pelo fato da dengue possuir grande capacidade de transmissão e de causar danos graves e letais, nas mais diversas populações, tanto em sua forma clássica que apresenta sintomas leves, quanto em sua forma hemorrágica, na qual pode ser letal (BESERRA; CASTRO JUNIOR, 2008), sua importância no Brasil e o no Mundo vem crescendo, de forma que se torna imprescindível divulgar conhecimento dos aspectos clínicos e epidemiológicos dessa doença. Portanto, o objetivo deste trabalho foi sintetizar as informações disponíveis acerca do aedes aegypti e a dengue, abrangendo aspectos gerais e panorama da dengue no Brasil e no Mundo, a fim de compilar material educativo.

\section{Desenvolvimento}

\subsection{Metodologia}

Os estudos relacionados ao tema foram encontrados mediante busca na Biblioteca Virtual em Saúde (BVS), PubMed e Embase utilizando as seguintes palavras-chaves: dengue; aedes aegypti; saúde pública na versão, tanto em português quanto em inglês, e combinadas entre si. Também foram consultados documentos do Ministério da Saúde e Organização Mundial da Saúde sobre o manejo da dengue. Não houve recorte temporal para inclusão dos estudos.

\subsection{O Ae. Aegypti}

$\mathrm{O}$ mosquito Ae. aegypti pertence à família Culicidae, à ordem Diptera e subordem Nematocera, que incluem 40 gêneros distribuídos nas subfamílias Anophelinae e Culicinae. Há cerca de 3350 espécies descritas no Mundo, sendo que, destas, 490 ocorrem no Brasil (BRASIL, 2009).

O ciclo de vida básico dos mosquitos, normalmente, consiste em ovo, quatro estágios larvais, a pupa e o adulto (Figura 1). Os ovos podem ser depositados em lâmina de água (Culex sp.), na transição entre o ambiente aquático e terrestre (Aedes e Anopheles spp.), em solo úmido (Psorophora sp.) ou em vegetação (Mansonia sp.) (HIGGS, 2005).

Figura 1 - Ciclo de vida do Aedes Aegypti

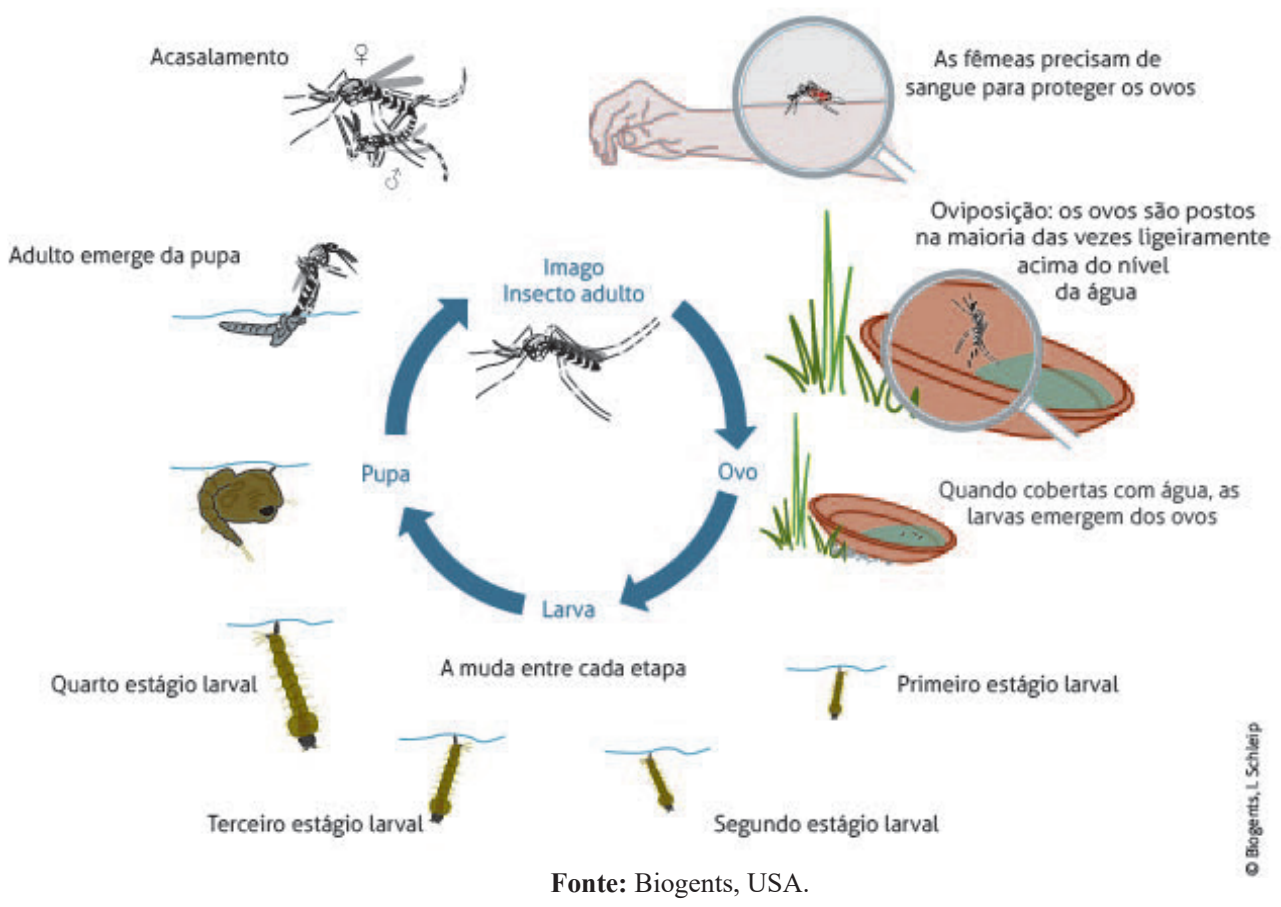

Da oviposição à fase adulta decorrem em média 10 dias em condições favoráveis de temperatura e disponibilidade de alimentos. Os ovos são depositados, individualmente, pelas fêmeas nas paredes internas de recipientes, próximos à superfície da água, embora as posturas possam ser realizadas diretamente na água (GOMES et al., 2006).

Esses insetos (Figura 2) possuem listras brancas no tronco, cabeça e pernas, uma característica marcante, que o diferencia dos demais mosquitos (DONALISIO; VIDRO, 2002). 
Figura 2 - Características do mosquito Aedes Aegypti

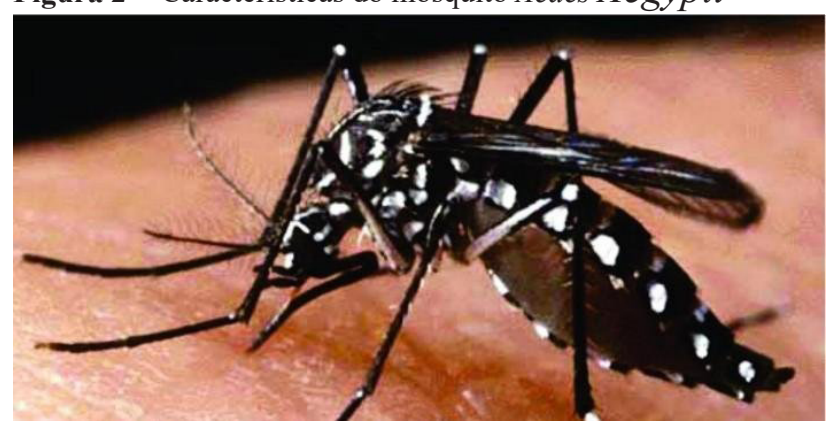

Fonte: Secretaria de Saúde do RS.

A relação entre a densidade populacional da espécie e fatores abióticos tem se mostrado diretamente proporcional, principalmente, no que se refere à pluviosidade e temperatura. Apesar de Ae. aegypti conseguir manter uma população considerável durante as estações mais secas, se reproduzindo em criadouros semipermanentes e independentes das chuvas, como caixas de água, cisternas e tonéis, sendo na estação chuvosa que a abundância aumenta significativamente (HIGGS, 2005).

Além disso, a relação direta entre abundância de $A e$. Aegypti e temperatura é comumente descrita na literatura: para Ae. Aegypti, a taxa de metabolismo aumenta nos meses quentes e seu ciclo reprodutivo se torna mais rápido, durando até oito dias. O aumento da temperatura torna o período extrínseco de incubação do vírus no inseto mais rápido (HALSTEAD, 2008).

Diversas circulações dos vetores culicídeos emergem sob diferentes feições paisagísticas, sendo a exposição das pessoas, em ambiente silvestre, aos mosquitos infectados a mais comum. Ochlerotatus, Stegomyia, Howardina e Protomacleaya são subgêneros de Aedes, pertencentes à família Culicidae, existentes no Brasil. Entretanto, apenas os subgêneros Stegomyia e Ochlerotatus reúnem espécies de Aedes com importância epidemiológica (CODEÇO et al., 2010).

Apesar de o Ae. Aegypti estar amplamente disseminado nos Estados brasileiros, seus vetores naturais têm baixa capacidade para transportá-los, além das matas. A etiologia do Ae. Aegypti beneficia sua ampla dispersão, favorecida nos ambientes urbanos, preferencialmente, no intra e no peridomicílio humano. Raramente são encontrados em ambientes semissilvestres ou nos quais não há presença intensa do homem (GLASSER et al., 2002).

\subsection{Dengue}

\subsubsection{Aspectos gerais da dengue}

A dengue é uma doença, uma arbovirose, transmitida principalmente pela picada do mosquito Ae. Aegypti. Essa vem preocupando as autoridades em saúde pública, em virtude de sua ampla distribuição e capacidade de ocasionar casos graves e letais, tanto na forma clássica ou hemorrágica (BESERRA; CASTRO JR., 2008).
Pode ser assintomática ou sintomática, podendo evoluir para casos graves, como a dengue hemorrágica. O quadro clínico depende de fatores relacionados ao hospedeiro e ao próprio vírus, tais como: virulência, idade do hospedeiro, infecção primária e/ou infecção secundária, estado nutricional e fatores genéticos (BRASIL, 2009).

Provoca desde infecções inaparentes até quadros de hemorragia e choque, podendo evoluir para óbito. É uma doença sazonal, que ocorre com maior frequência em períodos quentes e de alta umidade, já que tais condições favorecem a proliferação do mosquito transmissor (GARCIA, 2019). Além disso, o vírus possui quatro tipos presentes: DENV-1, DENV2, DENV-3, DENV-4. No Brasil, atualmente, os quatro sorotipos estão atuantes, o que mostra que há uma epidemia contínua (DRUMOND, 2020).

Quanto a sua classificação, na Dengue clássica o quadro clínico é muito variável. A primeira manifestação é a febre alta (39 a $40{ }^{\circ} \mathrm{C}$ ), de início abrupto, seguida de cefaleia, mialgia, prostração, artralgia, anorexia, astenia, dor retroorbital, náuseas, vômitos, exantema e prurido cutâneo. Hepatomegalia dolorosa pode ocorrer, ocasionalmente, desde o aparecimento da febre. Alguns aspectos clínicos dependem, com frequência, da idade do paciente. A dor abdominal generalizada pode ocorrer, principalmente, nas crianças (BRASIL, 2002).

Os adultos podem apresentar pequenas manifestações hemorrágicas, como petéquias, epistaxe, gengivorragia, sangramento gastrointestinal, hematúria e metrorragia. A doença tem uma duração de 5 a 7 dias. Com o desaparecimento da febre, há regressão dos sinais e sintomas, podendo ainda persistir a fadiga (DRUMOND, 2020).

Já na Febre Hemorrágica da Dengue (FHD), os sintomas iniciais são semelhantes aos da dengue clássica, porém evoluem rapidamente para manifestações hemorrágicas e/ ou derrames cavitários e/ou instabilidade hemodinâmica e/ou choque. Os casos típicos da FHD são caracterizados por febre alta, fenômenos hemorrágicos, hepatomegalia e insuficiência circulatória. Um achado laboratorial importante é a trombocitopenia com hemoconcentração concomitante. A principal característica fisiopatológica associada ao grau de severidade da FHD é a efusão do plasma, que se manifesta através de valores crescentes do hematócrito e da hemoconcentração (BRASIL, 2002).

A prova do laço positiva é comumente encontrada entre as manifestações hemorrágicas. Ela consiste em se obter, através do esfignomanômetro, o ponto médio entre a pressão arterial máxima e mínima do paciente, mantendo-se esta pressão por 5 minutos; quando positiva aparecem petéquias sob o aparelho ou abaixo do mesmo. Se o número de petéquias for de 20 ou mais em um quadrado desenhado na pele com $2,3 \mathrm{~cm}$ de lado, essa prova é considerada fortemente positiva (BARROS, 2008).

Nos casos graves de FHD, o choque geralmente ocorre entre o $3^{\circ}$ e $7^{\circ}$ dia de doença, precedido por um ou mais sinais de alerta. O choque é decorrente do aumento da permeabilidade 
vascular, seguido de hemoconcentração e falência circulatória. É de curta duração e pode levar ao óbito em 12 a 24 horas ou para recuperação rápida, após terapia anti-choque apropriada (BRASIL, 2002). Conforme estabelecido pela OMS (1995), todo paciente com dengue necessita ter os quatro critérios para que a doença possa ser classificada como FHD (Quadro 1).

Quadro1 - Critérios de classificação para dengue hemorrágica

\begin{tabular}{|r|l|}
\hline \multicolumn{3}{|c|}{ Descrição dos critérios de classificação } \\
\hline 1 & Febre ou história de febre recente de até sete dias; \\
\hline 2 & Trombocitopenia (contagem plaquetária <100.000/ mm3); \\
\hline 3 & $\begin{array}{l}\text { Tendências hemorrágicas evidenciadas por um ou mais } \\
\text { dos seguintes sinais: prova do laço positiva, petéquias, } \\
\text { equimoses ou púrpuras, sangramentos de mucosas do trato } \\
\text { gastrointestinal e outros; }\end{array}$ \\
\hline & $\begin{array}{l}\text { Extravasamento de plasma devido ao aumento da } \\
\text { permeabilidade capilar, manifestado por: hematócrito } \\
\text { apresentando aumento de 20\% sobre o basal na admissão; } \\
\text { queda do hematócrito em } 20 \% \text { após tratamento adequado; } \\
\text { ou presença de derrame pleural, ascite e hipoproteinemia. }\end{array}$ \\
\hline
\end{tabular}

Fonte: Brasil (2016).

A FHD é classificada de acordo com sua gravidade em quatro graus (OMS, 1995), que estão abaixo relacionados.

Quadro 2 - Níveis de classificação da gravidade da dengue hemorrágica

\begin{tabular}{|l|l|}
\hline \multicolumn{1}{|c|}{ Grau } & \multicolumn{1}{c|}{ Classificação } \\
\hline Grau I & $\begin{array}{l}\text { Febre acompanhada de sintomas inespecíficos, } \\
\text { em que a única manifestação hemorrágica é a } \\
\text { prova do laço positiva. }\end{array}$ \\
\hline Grau II & $\begin{array}{l}\text { Além das manifestações do grau I, ocorrem } \\
\text { hemorragias espontâneas leves (sangramentos } \\
\text { de pele, epistaxe, gengivorragia e outros). }\end{array}$ \\
\hline Grau III & $\begin{array}{l}\text { Colapso circulatório com pulso fraco e rápido, } \\
\text { estreitamento da pressão arterial ou hipotensão, } \\
\text { pele pegajosa e fria, e inquietação. }\end{array}$ \\
\hline $\begin{array}{l}\text { Grau IV ou } \\
\text { Síndrome do } \\
\text { Choque da } \\
\text { Dengue }\end{array}$ & $\begin{array}{l}\text { Choque profundo com ausência de pressão } \\
\text { arterial e pressão de pulso imperceptível. }\end{array}$ \\
\hline Fonte: Brasil (2016).
\end{tabular}

\subsubsection{Transmissão}

A transmissão da dengue está relacionada aos inúmeros fatores de risco, como: migrações, crescimento populacional, urbanização inadequada, funcionamento dos serviços de saúde e densidade da população (TAUIL, 2006). A densidade da população é um dos fatores mais importantes para que se defina um padrão de transmissão da dengue, visto que em médias e grandes cidades a transmissão e a infestação são maiores, além da limitação de recursos e profissionais para a prevenção da dengue (GOMEZ; DANTES, 1995).

Basicamente, a transmissão ocorre quando após repasto sanguíneo, quando o mosquito fica apto a transmitir o vírus, depois de 8 a 12 dias de incubação. A transmissão mecânica também é possível, quando o repasto é interrompido e o mosquito, imediatamente, se alimenta de um hospedeiro suscetível próximo. O período de incubação varia de três a 15 dias, sendo, em média, de 5 a 6 dias. Enquanto houver presença de vírus no sangue humano (período de viremia) ainda há risco de transmissão. Este período começa um dia antes do aparecimento da febre e vai até o $6^{\circ}$ dia da doença. No entanto, não há transmissão por contato direto de um doente ou de suas secreções com uma pessoa sadia, nem de fontes de água ou alimento (BRASIL, 2002).

$\mathrm{O}$ mosquito adquire o vírus ao se alimentar do sangue de doente, que se encontra na fase de viremia. O vírus vai se localizar nas glândulas salivares do mosquito, nas quais se prolifera e aí permanece, o que deixa o artrópode infectante durante toda a sua vida (MS, 2010). Uma vez infectada, a fêmea do mosquito inocula o vírus junto com a sua saliva ao picar a pessoa sadia. Além disso, a fêmea também faz a transmissão transovariana do vírus para a sua prole, favorecendo a expansão da doença (FIOCRUZ, 2020).

Depois de inoculado, no hospedeiro humano, o vírus entra nas células, se replica, produz progenitores virais e se inicia, então, a fase de viremia, com posterior distribuição do vírus para todo o organismo. Não estão totalmente esclarecidos os sítios de replicação viral no homem, mas as evidências apontam para as células da linhagem monocítica-macrofágica de órgãos linfoides, pulmões e fígado como os principais locais (BHAMARAPRAVATI, 1997).

A replicação viral estimula os monócitos e, indiretamente, linfócitos a produzirem citocinas. Algumas dessas vão ter efeito pró-inflamatório e vão ser responsáveis pelo aparecimento de sintomas como a febre. Outras estimulam a produção de anticorpos, que se ligam aos antígenos virais, formando imunocomplexos (FONSECA, 2002).

Os anticorpos IgM antidengue começam a ser produzidos, a partir do quinto e sexto dia (GUZMÁN; KOURI, 2002). Esses são capazes de neutralizar o vírus de forma que seu aparecimento marca o declínio da viremia e permanecem detectáveis no soro por aproximadamente dois meses (TSAI, 2005).

Os anticorpos IgG antidengue surgem após um período de sete a dez dias de evolução, sobem muito na convalescença e voltam a cair, persistindo em títulos baixos por toda a vida, conferindo imunidade do sorotipo específico. Na infecção secundária, em função de linfócitos de memória, a produção de IgG começa mais precocemente e atinge níveis mais elevados (GUZMÁN; KOURI, 2002). Por existirem quatro sorotipos da dengue, que em síntese acarretam os mesmos sintomas, é possível ter dengue até quatro vezes, pois cada vez que a pessoa é infectada por um sorotipo se torna imune a esse (BRASIL, 2016).

\subsubsection{Diagnóstico e Tratamento}

O diagnóstico é muito importante para o tratamento e prognóstico da dengue. Hoje em dia, o diagnóstico é feito através de técnicas variadas, baseadas em dados clínicos, epidemiológicos e laboratoriais. Sem ainda haver um consenso mundial sobre qual seria o melhor método, no Brasil, para diagnóstico da dengue são empregados exames inespecíficos, 
como a "prova do laço" e o hemograma e, exames específicos, como a sorologia via isolamento viral e identificação de anticorpos (BIASSOTI et al., 2017).

$\mathrm{Na}$ dengue clássica não há tratamento específico. A medicação é apenas sintomática, com o uso de analgésicos e antitérmicos (paracetamol e dipirona). Devem ser evitados os salicilatos e os anti-inflamatórios não hormonais, já que seu uso pode favorecer o aparecimento de manifestações hemorrágicas e acidose. O paciente deve ser orientado a permanecer em repouso e iniciar hidratação oral (BRASIL, 2002).

$\mathrm{Na}$ FHD, os pacientes devem ser observados, cuidadosamente, para identificação dos primeiros sinais de choque. O período crítico será durante a transição da fase febril para a afebril, que geralmente ocorre após o terceiro dia da doença. Em casos menos graves, quando os vômitos ameaçarem causar desidratação ou acidose, ou houver sinais de hemoconcentração, a reidratação pode ser feita em nível ambulatorial (BARROS, 2008).

A OMS/MS publicou, em 2016, uma atualização sobre o manejo clínico da dengue, demonstrado abaixo, na figura 3, especificamente, o manejo da FHD (BRASIL, 2016).

Figura 3 - Fluxograma do manejo clínico da Dengue Hemorrágica

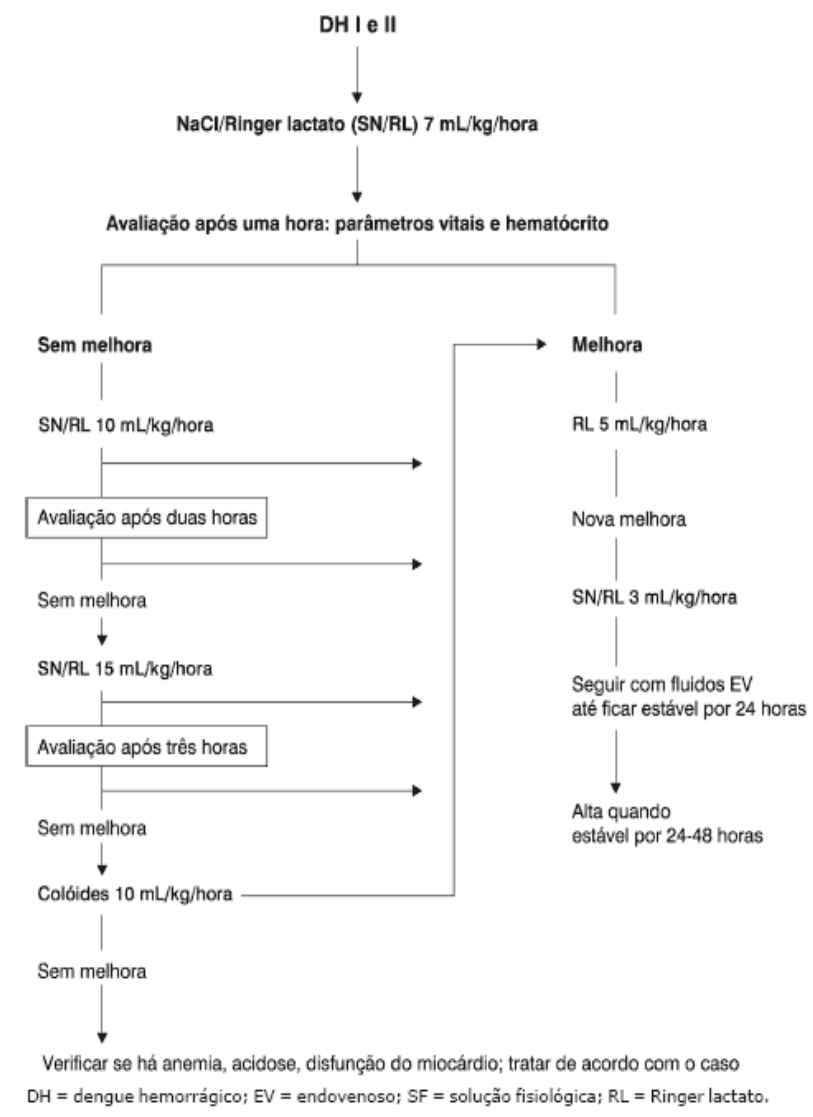

$\mathrm{DH}=$ dengue hemorrágico; $\mathrm{EV}=$ end
Fonte: Shingui et al., (2007).

O prognóstico da dengue hemorrágica vai depender do diagnóstico e tratamento precoces, a fim de evitar o agravamento da doença. Sem tratamento, a taxa de mortalidade da FHD é de 40 a 50\%. Com o diagnóstico precoce, cuidado adequado e tratamento, essa taxa é diminuída para $1 \%$. Não existe vacina ou medicação para o combate à doença, o que seria de grande importância para a diminuição de casos graves e não graves, incluindo a mortalidade (SHINGUI et al., 2007).

Atualmente, não há quimioterapia ou vacina disponível para esta doença e a única maneira de controlá-la é erradicar ou reduzir o vetor em níveis extremamente baixos (JUAN, 2002), comumente por meio do uso de inseticidas, uma vez que seu emprego consiste em uma estratégia comum aos programas de doenças, cujos agentes são transmitidos por vetor em todo o Mundo (CESARINO et al., 2014).

Além disso, um importante e grande desafio, em decorrência de todas as patologias envolvidas e transmitidas através do vetor Ae. Aegypti, é o controle desse vetor (ZARA et al., 2016). Existe a recomendação para que haja um controle de forma integrada, através dos meios de restrição disponíveis, a fim de manter a população de vetores aedes aegypti em um nível mínimo aceitável e, dessa maneira, evitando a transmissão (DONALÍSIO; GLASSER, 2002).

Muitas das informações sobre a dengue e os meios de prevenção estão disponíveis, tais como: evitar o acúmulo de água em potes e locais nos quais a água possa ficar armazenada, colocar areia em vasos de plantas, telas em janelas se possível, realizar limpeza frequente de calhas, piscinas, aquários, e demais locais que armazenam água, utilizar repelentes e inseticidas (SOUZA et al., 2020).

Em função de sua disseminação, a dengue é um problema de saúde pública, e deve ser alvo de todos os órgãos estatais, tais como: secretarias de saúde, de vigilância epidemiológica e de centros de controle de infecção. Para que todas as medidas de prevenção sejam executadas, de forma efetiva, também é necessária a participação comunitária, assim como conscientização sobre a dengue e seus agravos (ROQUE et al., 2017).

\subsection{Histórico e panorama da dengue no Brasil e no Mundo}

Como importante arbovirose, a metade dos países do Mundo são endêmicos de dengue (AYUKEKBONG et al., 2017), com número de casos e aumento de surtos dez vezes mais que nos últimos trinta anos. A doença é encontrada em pelo menos cem países tropicais e subtropicais, incluindo os países da África, Sudeste Asiático, Pacífico Ocidental, Américas, Caribe e no Mediterrâneo Oriental (PARKASH; SHUEB, 2015).

Os primeiros surtos de dengue notificados datam de 1779 e 1780, na Ásia, África e América do Norte. Entretanto, há relatos de uma epidemia compatível com esta doença em uma enciclopédia chinesa datada de 265-420 d.C. (MAYER et al., 2017).

A Segunda Guerra Mundial trouxe mudanças ecológicas, demográficas e epidemiológicas que permitiram que o vetor atingisse altas densidades, facilitando a dispersão de sorotipos de dengue vírus (DENV) entre diversas regiões geográficas. 
Especula-se que, provavelmente, o vírus chegou ao Brasil no período colonial, trazido da África pelos escravos (PAIXÃO et al., 2018).

Houve durante muitas décadas, um programa iniciado, em 1946, pela Organização Pan-Americana da Saúde (OPAS), que foi realizado no intuito de erradicar o Ae. Aegypti, prevenindo epidemias de febre amarela urbana e dengue nos países da América Continental. Entretanto, no início dos anos 1970, a não continuidade do programa em países que já haviam conquistado a erradicação acarretou lenta reinfestação pelo vetor, sendo que, em 1987, quase todos os países já apresentavam Ae. Aegypti em seu território (VASCONCELOS, 2002).

No Brasil, o vetor Ae. Aegypti teve seus primeiros registros documentados, em 1898, por Lutz e, em 1899, por Ribas (FRANCO, 1969). Entretanto, há referências de epidemias de dengue desde 1916, em São Paulo, e em 1923 no Rio de Janeiro (XAVIER et al., 2018). Contudo, a primeira epidemia documentada clínica e, laboratorialmente, ocorreu entre 19811982 em Boa Vista, Roraima. Em 1986-1987, uma epidemia de grandes proporções assolou a cidade do Rio de Janeiro e, a partir daí, novas epidemias ocorreram em diversos Estados. Em 2002, ocorreu uma das maiores incidências da doença no Brasil, com quase 700.000 casos notificados. Depois disso, houve diminuição significativa do número de casos da doença em 2003 e 2004, voltando a aumentar em 2005 (BRASIL, 2010).

Nas últimas décadas, o país viveu quatro grandes epidemias associadas à alternância do sorotipo viral predominante: DENV-1, DENV-3, DENV-2, e DENV-4, em 1998, 2002, 2008 e 2010, respectivamente (MANIERO et al., 2016).

Modificações ecológicas produzidas pelo homem podem aumentar a prevalência dos vetores, criar novos reservatórios e induzir certos patógenos a se adaptarem a novos ciclos de manutenção. Apesar dos grandes avanços científicos alcançados, nas últimas décadas, doenças novas ou mesmo aquelas que se imaginavam controladas são, frequentemente, encontradas como personagens de novos surtos, como dengue (CALERO, 2002).

Os fatores determinantes para a expansão, atualmente, observada da dengue são multifatoriais e incluem a evolução do vírus. Entre eles estão os fatores socioeconômicos, como crescimento populacional, recursos econômicos limitados e a urbanização; aquecimento global; assim como viagens e comércio globais (MURRAY et al., 2013).

De acordo com o mapa de consenso global da dengue (Figura 4), a dengue é endêmica em diversas partes do Mundo, mas especificamente também na América do Sul, e no Brasil. O mapa abaixo mostra os locais de risco para dengue, nos meses de maio/junho/julho de 2020, assim como os locais já endêmicos e que precisam de uma atenção maior, por parte das autoridades epidemiológicas e de saúde. Tendo um total de 818 alertas de identificação de áreas de risco para dengue nos meses já citados.

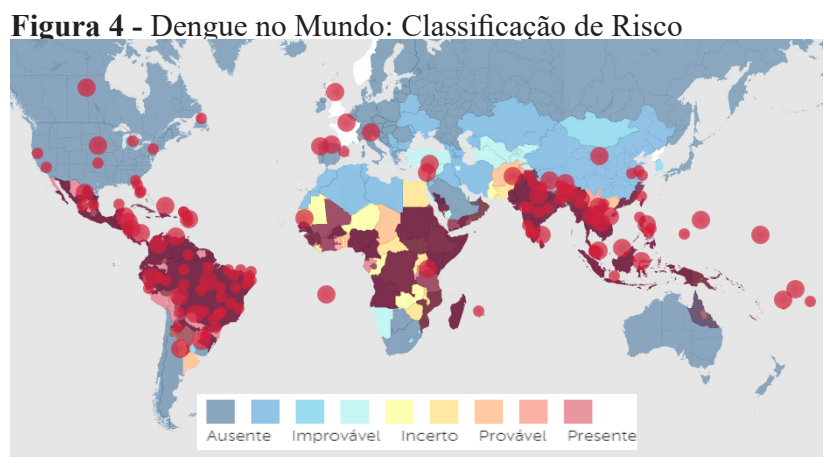

Fonte: Adaptado de Centers for Disease Control and Prevention CDC (2020).

As regiões mais afetadas pela dengue, no Brasil, segundo dados do Ministério da Saúde (2019), são as Sudeste e CentroOeste, pois concentram a maior parte do número de casos notificados no país em 2019. A região Sudeste concentrou cerca de $60 \%$ (32.821) do número total de casos notificados, no Brasil, em 2019 (54.777). Em seguida, estão as regiões: Centro-Oeste, que apresentou 10.827 casos de dengue; Norte com 5.224 casos; Nordeste com 4.105 casos e Sul com 1.800 casos.

Em relação à incidência, as regiões Centro-Oeste e o Sudeste foram as que apresentaram os dados mais elevados: 67,3 casos para 100 mil habitantes e 37,4 casos para 100 mil habitantes, respectivamente. E quando se comparam os dados entre as regiões do país durante o mesmo período (2018/2019), a região que apresenta o maior crescimento de casos é a região Sul, $597,7 \%$ e a região Sudeste teve um aumento de $472,6 \%$. A região Norte aumentou em $233 \%$ e a região Nordeste com $37,6 \%$ de crescimento. Porém, a região Centro-Oeste foi a única que apresentou leve redução de 5,4\% (MS, 2019).

\section{Conclusão}

A dengue, causada pelo mosquito Aedes aegypti, é um grave problema de saúde pública e endêmica em vários países do Mundo, incluindo o Brasil. Apresenta diversas condições facilitadoras de sua transmissão e quatro diferentes sorotipos, que propiciam reinfecção. Ainda não possui um tratamento específico e nem vacina disponível. Atualmente, o meio mais eficaz de evitar sua propagação é pela prevenção e controle do vetor. Para que isso ocorra, as pessoas em todo Mundo devem ter o conhecimento e informações necessárias sobre prevenção, diagnóstico e tratamento, a fim de evitar sua transmissão, disseminação e letalidade.

Ademais, reforça-se a necessidade de levar os conhecimentos disponíveis sobre a dengue, a população e os governantes, sobre os meios de prevenção e tratamento precoce com o intuito de futuramente ter um tratamento específico, controle efetivo e erradicá-la.

\section{Referências}

AMARAL, R.J.V.; DANSA-PETRESTSKI, M. Tópicos avançados em entologia molecular. INCTEM. Capítulo 14: Interação Patógeno - Vetor: Dengue. Rio de Janeiro, 2012. 
AYUKEKBONG, JA. et al. Value of routine dengue diagnosis in endemic countries. World J. Virol., v.6, n.1, p.9-16, 2017. doi:10.5501/wjv.v6.i1.9.

BARROS, L. et al. Hematological and serological findings of individuals with suspicion of Dengue fever infection. Rev. Bras. Hematol. Hemoter., v.30, n.5, p.363-366, 2008. doi: 10.1590/ S1516-84842008000500007.

BESERRA, E.; CASTRO, F. Compared biology of populations of Aedes (Stegomyia) aegypti (L.) (Diptera: Culicidae) of Paraiba State, Brazil. Neotro. Entomol., v.37, p. 81-85, 2008. doi: 10.1590/S1519-566X2008000100012.

BHAMARAPRAVATI, N. Pathology of dengue infections. In: GUBLER, D.J.; KUNO, G. Dengue and dengue hemorrhagic fever. Londres: Cab International, 1997. p.115-132.

BIASSOTI, A.V.; ORTIZ, M.A.L. Diagnóstico laboratorial da Dengue. Rev. Uningá Rev., v.29, n.1, p.122-126, 2017.

BRASIL. Ministério da Saúde. Secretaria de Vigilância em Saúde. Informe Epidemiológico da Dengue - Análise de Situação e Tendências - 2010. Brasília: MS, 2010.

BRASIL. Ministério da Saúde. Fundação Nacional de Saúde. Dengue: aspectos epidemiológicos, diagnóstico e tratamento. Brasília: Fundação Nacional de Saúde, 2002.

BRASIL. Ministério da Saúde. Secretaria de Vigilância em Saúde. Departamento de Vigilância Epidemiológica. Diretrizes nacionais para prevenção e controle de epidemias de dengue. Brasília: MS, 2009.

BRASIL. Ministério da Saúde. Secretaria de Vigilância em Saúde. Departamento de Vigilância das Doenças Transmissíveis. Dengue: diagnóstico e manejo clínico: adulto e criança. Brasília: MS, 2016.

CESARINO, M.B. et al. A difícil interface controle de vetores - atenção básica: inserção dos agentes de controle de vetores da dengue junto às equipes de saúde das unidades básicas no município de São José do Rio Preto, SP. Saude Soc., v.23, n.3, p.1018-1032, 2014. doi: 10.1590/S0104-12902014000300023.

CODEÇO, C. et al. Interações ecológicas e doenças transmissíveis. Oecolol. Australis, v.14, n.3, p.588-590, 2010.

del rey calero, j. enfermedades infecciosas Emergentes y Reemergentes. Anal. Med. Interna, v.19, n.9, p.443-445, 2002.

DONALISIO, M.R.; VIDRO, C.M. Vigilância entomológica e controle de vetores da dengue. Rev. Bras. Epidemiol., v.5, n.3, p.259-279, 2002. doi: 10.1590/S1415-790X2002000300005.

DRUMOND, B. et al. Dinâmica espaço-temporal da dengue no Distrito Federal, Brasil: ocorrência e permanência de epidemias. Ciênc. Saúde Coletiva, v.25, n.5, p.16411652, 2020. doi: 10.1590/1413-81232020255.32952019.

FIOCRUZ - FUNDAÇÃO OSWALDO CRUZ. Vetor da dengue na Ásia, A. albopictus é alvo de estudos. Rio de Janeiro: FIOCRUZ, 2020.

FONSECA, B.A.L.; FONSECA, S.N.S. Dengue virus infections. Curr. Opin. Pediatr., v.14, n.1, p. 67-71, 2002. doi: 10.1097 00008480-200202000-00012.

FRANCO, O. Reinfestação do Pará por Aedes aegypti. Rev. Bras. Malariol. Doenças Trop., v.21, n.4, p.729-731, 1969.

GARCIA, C.L. et al. Descrição do problema da dengue com enfoque na determinação social da saúde em uma comunidade: estudo de campo. Mem. Inst. Investig. Ciênc. Saúde, v.17, n.2, p.615, 2019. doi: 10.18004/mem.iics/1812-9528/2019.017.02.06015 .
GLASSER, C.M.; GOMES, A.C. Clima e sobreposição da distribuição de Aedes aegypti e Aedes albopictus na infestação do estado de São Paulo. Rev Saúde Pública v.36, p.166-172, 2002. doi: 10.1590/S0034-89102002000200008.

GOMES, A.S.; SCIAVICO, C.J.S.; EIRAS, A.E. Periodicidade de oviposição de fêmeas de Aedes aegypti (Linnaeus, 1762) (Diptera: Culicidae) em laboratório e campo. Rev. Soc. Bras. Med. Trop. v.39, n.4, p.327-332, 2006. doi: 10.1590/S003786822006000400002 .

GÓMEZ-DANTÉS， H.; RAMOS-BONIFAZ， B.; TAPIACONYER, R. Risco de transmissão da dengue: um espaço para estratificação. Saúde Pública do México, v.37, p.88-97, 1995.

GUZMÁN, M.; KOURI, G. Dengue: an update. Lancet Infect Dis., v.2, p.33-42, 2002. doi: 10.1016 / s1473-3099 (01) 00171-2.

HALSTEAD, S. Dengue Virus-Mosquito Interactions. Ann. Rev. Entomol., v.53, p. 273-91, 2008. doi: 10.1146/annurev. ento.53.103106.093326.

HIGGS, S. Care, maintenance and experimental infection of mosquitoes. Biology of Disease Vectors. New York: Elsevier Academic Press, 2005.

MANIERO, V. et al. Dengue, chikungunya e zika vírus no brasil: situação epidemiológica, aspectos clínicos e medidas preventivas. Alm. Multidiscip. Pesq., v.1, n.1, p.118-45, 2016.

MAYER, S.V.; TESH, R.; VASILAKIS, N. The emergence of arthropod-borne viral diseases: A global prospective on dengue, chikungunya and zika fevers. Acta Trop. v.166, p. 155-163, 2017 doi: 10.1016 / j.actatropica.2016.11.020.

BRASIL. Ministério da Saúde. Fundação Nacional de Saúde Dengue - Instruções para pessoal de combate ao vetor: Manual de normas técnicas. Brasília: MS, 2001.

MURRAY, A.N.; QUAM, M.; WILDER, S.A. Epidemiology of dengue: past, present and future prospects. Clin Epidemiol. v.5, p. 299-309, 2013. doi: 10.2147 / CLEP.S34440.

PAIXÃO, E.; TEIXEIRA， M.G.; RODRIGUES， L. Zika, chikungunya and dengue: the causes and threats of new and reemerging arboviral diseases. BMJ Glob Health. v.3, n. 1, p.e000530, 2018. doi: 10.1136 / bmjgh-2017-000530.

PARKASH, O.; SHUEB, H.N. Diagnosis of Dengue Infection Using Conventional and Biosensor Based Techniques. Viruses. v.7, n.10, p. 5410-27, 2015. doi: 10.3390 / v7102877.

ROQUE, D. M.; ALMEIDA, F. M.; MOREIRA, V. S. Política Pública de Combate à Dengue e os Condicionantes Socioeconômicos. In: ENCONTRO BRASILEIRO DE ADMINISTRAÇÃO PÚBLICA. 2017. Viçosa. Anais... Universidade Federal de Viçosa (UFV), 2017.

SOUZA, K.R. et al. Saberes e práticas sobre controle do Aedes aegypti por diferentes sujeitos sociais na cidade de Salvador, Bahia, Brasil. Cad. Saúde Pública, v.34, n.5, e00078017, 2018. doi: 10.1590/0102-311x00078017.

TAUIL, P.L. Perspectivas de controle de doenças transmitidas por vetores no Brasil. Rev. Soc. Bras. Med. Trop., v. 39, n. 3, p. $275-$ 277, 2006. doi: 10.1590/S0037-86822006000300010.

TSAI, F.; VAUGHN, D.; SOLOMON, T. Flaviviruses (Yellow Fever, DengueHemorrhagic fever, Japanese Encephalitis, St Louis Encephalitis, Tick-borne Encephalitis). In: MANDELL, G.; BENNETT J.; DOLIN, R. Principles and practice of infectious diseases. Philadelphia: Elsevier-Churchill-Livingstone, 2005. doi: 10.1016/B978-1-4557-4801-3.00155-7.

VASCONCELOS, P.F.C. Febre amarela: reflexões sobre a doença, as perspectivas para o século XXI e o risco da reurbanização. Rev. Bras. Epidemiol., v.5, n.3, p.244-258, 2002. doi: 10.1590/S1415- 
790X2002000300004.

WERMELINGER, E.D. Métodos de controle de insetos vetores: um estudo das classificações. Rev. Pan-Amazônica Saúde. v.4, n.3, p.49-54, 2013. doi:10.5123/S2176-62232013000300007.
WRBU, Walter Reed Biosystematics Unit. Systematic catalog of Culicidae. 2014.

XAVIER, A.L.R. et al. Manifestações clínicas na dengue: diagnóstico laboratorial. Rev. Bras. Med., v.102, n.2, p.7-14, 2014. 